\title{
APROXIMACIÓN DIDÁCTICA A LA TERMODINÁMICA CON MODELOS Y LITERATURA DE CIENCIA FICCIÓN
}

\section{Didactical approximation to the thermodynamics with models and science fiction's literature}

\author{
Raúl Oscar Zamorano ${ }^{1}$ \\ Lucrecia Ethel Moro ${ }^{2}$ \\ Horacio Miguel Gibbs ${ }^{3}$
}

Resumen: El estudio de la energía y sus transformaciones en el nivel educativo medio se circunscribe en general a aspectos relacionados con su conservación y transferencia. La degradación de la energía recibe escasa atención y el concepto de entropía es considerado misterioso y difícil de comprender. Realizamos una investigación descriptiva, con la hipótesis de que se facilitará la compresión de los conceptos si complementamos la instrucción con figuras del lenguaje de ciencia ficción, que son básicamente analógicas. Encontramos en dos cuentos de "buena" ciencia ficción la posibilidad de abordar el estudio de la termodinámica en dos niveles explicativos, el fenomenológico y el de los aspectos microscópicos y estadísticos de la materia. Comprobamos su función como modelo didáctico analógico ya que abstrae los conceptos y relaciones mediante una situación inteligible para el estudiante y comparte un isomorfismo estructural con el modelo teórico.

Palabras clave: Termodinámica. Energía y entropía. Recursos didácticos. Ciencia ficción.

\begin{abstract}
Energy transformations teaching at secondary school, generally relate to conservation and transference. Moreover, the subject related to the dispersal of energy receives no special attention. There is a general consensus that entropy is one of the more difficult concepts. So we made an investigation with students from the last year of the secondary school who described their studies using the hypothesis of making it easier to understand these concepts if teaching is complemented with science fiction language with an analogical basis. Stories of "hard" science fiction provide a convenient tool for teaching thermodynamics at two levels: the phenomenological and the microscopic-statistical descriptions. So we prove their function as an analogical and didactical model because of their abstract concepts and their provision of an intelligible situation for students and the shared structural isomorphism with the theoretical model.
\end{abstract}

Keywords: Thermodynamics. Energy and entropy. Didactics resources. Science fiction.

\footnotetext{
${ }^{1}$ Graduado en Física. Docente, Departamento de Física, Facultad de Ciencias Exactas y Naturales, Universidad Nacional de Mar del Plata (UNMdelP). Mar del Plata, Argentina.<dpfisica@mdp.edu.ar>

${ }^{2}$ Graduada en Ingeniería Química, doctoranda en Educación Científica. Docente, Departamento de Química, Facultad de Ingeniería, UNMdelP. <lemoro@mdp.edu.ar>

${ }^{3}$ Graduado en Ingeniería Electrónica. Profesor, Colegio Nacional “Dr. A. U. Illia” - UNMdelP.

$<$ hgibbs@mdp.edu.ar>

${ }^{1}$ Funes 3550

Mar del Plata, Argentina
} 


\section{Introducción}

La energía y sus transformaciones presentan dificultades especiales para su conceptualización por lo que ha sido tratada, para su enseñanza, desde diversos enfoques (MARTÍNEZ; PÉREZ, 1997; MICHINEL; D’ALESSANDRO, 1994; ERIKSON, 1979). Pero en general se circunscribe, en el nivel educativo medio, a los aspectos relacionados con su conservación y transferencia (SOLBES; TARÍN, 1998). La degradación de la energía recibe escasa atención, aunque figura explícitamente en los planes de estudio.

El concepto de entropía, que cuantifica la degradación, es considerado como algo misterioso y difícil de comprender. Sin embargo la conservación y la degradación de la energía no deberían ser conceptos contradictorios sino complementarios. Por otra parte, no podemos dejar de lado los modelos microscópicos ni los aspectos estadísticos (ALONSO; FINN, 1995) que son los que nos pueden aclarar los términos confusos y corrientes de "orden" y "desorden".

Los modelos didácticos analógicos constituyen una estrategia original de enseñanza que implica la construcción activa, por parte de los estudiantes, de los elementos del dominio base de la analogía (GALAGOVSKY; ADÚRIZ-BRAVO, 2001).

Los modelos didácticos analógicos promueven articulaciones y transformaciones conceptuales. Las analogías son centrales para el entendimiento y el razonamiento (DE JONG, 1988; GOSWAMI; BROWN, 1990; HALFORD, 1993; GARNHAM; OAKHILL, 1994). Hemos comprobado frente a los estudiantes la ventaja pedagógica de complementar un enfoque macroscópico con las propiedades de las partículas constituyentes utilizando modelos microscópicos analógicos (ZAMORANO et al., 2006).

Otra forma de intermediación analógica para estimular la evolución conceptual es la narrativa, ya que las imágenes más poderosas son las que se originan desde las palabras (EGAN, 1999). Por eso la buena ciencia ficción es como un modelo didáctico analógico, ya que acerca al modelo teórico, abstrayendo sus conceptos y relaciones mediante una situación inteligible para el alumno. Propone también una metacognición, es decir una toma de conciencia de las transposiciones y aproximaciones necesarias para su validez conceptual.

En este trabajo evaluamos el poder de la narrativa como instrumento elaborador de situaciones pro-generativas en el proceso de enseñanza y aprendizaje utilizando textos literarios de ciencia ficción: Elegimos dos cuentos de "buena" ciencia ficción: La última pregunta de Isaac Asimov (1992) y Los cristales de Ítalo Calvino (1985). En el primero se discuten los conceptos de los principios de la termodinámica, conservación y degradación de la energía, crecimiento de la entropía y "muerte térmica del Universo". En el segundo aparecen los modelos microscópicos involucrados en la definición de entropía y se pueden analizar aspectos estadísticos sobre los términos "orden" y "desorden".

\section{Marco teórico}

Los modelos a ser enseñados, los que constituyen representaciones externas que tienden a un modelo cuantitativo, que se constituyen como un sistema hipotético-deductivo son los llamados modelos teoréticos. Los modelos teoréticos están contenidos dentro de una teo- 
ría general y no operan por analogía sino a través y por medio de una analogía subyacente. Las teorías generales son incontrastables mientras que los modelos teoréticos se pueden contrastar porque están acotados a conceptos definidos.

Para llegar al entendimiento de los modelos teoréticos se deben establecer procesos cognitivos que generen explicaciones. Esta actividad cognitiva requiere de la elaboración de situaciones intermedias para reconstruirlos y reformularlos. De modo que para comprender el modelo teorético se deben establecer previamente modelos conceptuales generativos que tengan la habilidad de reestructurar las representaciones y transferirlas. Este proceso implica una mezcla de conocimiento descriptivo (conocer qué) y procedimental (conocer cómo), además de estrategias y un control metacognitivo (EYLON; LINN, 1988).

El conocimiento cotidiano está condicionado por una epistemología espontánea de relaciones causales simples, que está dirigido por la percepción y es ampliamente compartida, lo que la hace difícil de modificar. Pero los modelos físicos a ser enseñados nos presentan siempre un resultado complejo de causas entrelazadas. Si pretendemos que los alumnos descubran las leyes solamente por medio de la observación y de la manipulación, los conduciremos a una gran confusión y al fracaso. Las leyes y teorías no son simplemente debidas a la recolección de datos, necesitan de suposiciones subsidiarias para su contrastación.

El entendimiento de los modelos teóricos se establecen a través de procesos cognitivos que generan justificaciones y predicciones. Un proceso cognitivo involucra operaciones de pensamiento que manipulan representaciones y éstas deben tener contenidos que la hagan semánticamente evaluables. El rol del docente debe ser el de tender puentes entre las representaciones de los alumnos y los modelos científicos.

Los textos de ficción utilizados para la divulgación científica o para la enseñanza se caracterizan por su facilidad de comprensión y se constituyen en disparadores del interés de los alumnos por el tema tratado. Pero lo más significativo es que implican a figuras del lenguaje que son básicamente analógicas cumpliendo con las condiciones para crear modelos generativos.

Como señalan Oliva et al. (2001) deberíamos plantear la analogía, no como un producto prefabricado que ha de ser aprendido, sino como un proceso en el que los alumnos puedan y deban aportar sus opiniones, tomar decisiones y en definitiva, contribuir abiertamente con su construcción. La analogía se genera a través de actividades de distinto tipo orientadas principalmente a fomentar la metacognición.

Desde el punto de vista conceptual, trataremos de que los estudiantes lleguen a contestar esta pregunta, la que será el motivo principal del curso: si la energía se conserva ¿por qué hay que "gastar" energía constantemente para que el mundo funcione?

Con los recursos propuestos nos planteamos desarrollar la formulación fenomenológica de la termodinámica, mediante la cual la entropía expresa cómo la cantidad de energía "disponible" en el universo disminuye constantemente porque se transfiere de los cuerpos calientes a los fríos, y va perdiendo la capacidad de realizar trabajo. Y de forma paralela, veremos la interpretación microscópica de la entropía, cuyo incremento se asocia a un aumento del desorden del sistema, es decir al incremento del grado de probabilidad de una configuración. 


\section{Narrativa, razón e imaginación}

La narrativa de ficción favorece la asimilación de los conceptos promoviendo la imaginación. Para G. Lakoff y M. Johnson (1991) la metáfora conceptual es un mecanismo cognitivo que permite que lo abstracto se comprenda en términos de lo concreto. La estructura cognitiva necesaria para la abstracción utiliza el mismo aparato conceptual que en las situaciones ordinarias del pensamiento cotidiano, es decir imágenes, esquemas y metáforas conceptuales. Y esto lleva a los procesos de modelización.

Para estos autores el pensamiento metafórico consuma la unión entre razón e imaginación "en consecuencia, la metáfora es racional imaginativa". La razón abarca los procesos de ordenar, categorizar y realizar inferencias mientras que la imaginación crea puentes conceptuales que permiten la transposición de propiedades de un dominio de partida hasta un dominio de llegada.

En los escritos pedagógicos se marcó tradicionalmente una diferencia entre la razón y la imaginación considerando que pertenecían a categorías incompatibles. Gastón Bachelard (1993) fue un pionero en estudiar sus relaciones, ya que la imaginación está presente tanto en el trabajo del literato como en la investigación científica, mostrando que no existe ningún conflicto entre ellas. Por otra parte se verifica una conexión entre la imaginación y los ámbitos motivacional y emocional sobre todo cuando podemos mantener, basada en relaciones analógicas, una secuencia de imágenes mentales en forma de una narrativa. Así, la capacidad imaginativa será una asociación entre afectividad, analogías y narrativa.

Las relaciones entre los objetos de la naturaleza y las limitaciones de nuestra percepción imponen obstáculos epistemológicos. Para Bachelard (1958), nuestras representaciones espontáneas enmascaran una falsa simplicidad y no constituirán conocimientos científicos aquellos que provengan de causalidades primitivas: "Se pretende que la imaginación sea la facultad de formar imágenes. Pero ella es más bien la facultad de deformar las imágenes proporcionadas por la percepción" (p. 7). Este autor afirma que tanto la razón como la imaginación son potencias activas que trabajan su objeto y que coinciden al rechazar las percepciones inmediatas. El literato descubre, más que inventa, ya que toda imaginación apunta a un objeto y "la correlación del soñador con el mundo es una correlación fuerte" (BACHELARD, 1982, p. 260).

En definitiva, la creación de modelos teoréticos de la ciencia, constantemente rectificados por nuevas hipótesis, tienen su correlato en la creatividad de imágenes del literato. La razón y la imaginación permiten una penetración metafísica de la realidad. Se advierte un carácter ontológico tanto en la labor científica como en la conciencia imaginativa, tratando de fusionarse con el objeto, y si bien esto no otorga posesión de la verdad, se adquiere una certidumbre objetiva que puede ser comunicada a los demás. Los procesos cognitivos de la imaginación literaria y de la racionalidad científica son los mismos.

\section{Ciencia ficción}

La ciencia ficción es un género, una forma literaria con matiz distinto, limitado y particular. Siempre ha sido usado como una forma de examinar las relaciones entre ciencia, 
tecnología y sociedad representando una fuente de inspiración para el desarrollo científico y como una forma de difundir sus ideas. Dentro de la cultura popular ha adquirido prestigio ya que en parte sus anticipaciones se han cumplido y reviste una importancia especial con respecto a la actitud que toma la gente sobre la actividad científica.

Aunque su mundo es restringido, en ocasiones se ha olvidado que el género pertenece a la literatura general. En ese sentido debemos considerar que incluye elementos que no pueden tenerse en cuenta al valorar simplemente una obra literaria. Así, suelen estimarse la originalidad y el rigor científico mientras se deja de lado el punto de vista estilístico. Isaac Asimov (1982) diferencia tres tipos de literatura de "falso fondo": la fantasía, la sátira social y la ciencia ficción.

La ciencia ficción como la fantasía y la sátira social se refiere a un 'fondo' que no es real. Al revés que la fantasía, su fondo no está completamente divorciado de la realidad, sino que representa de manera más o menos plausible una extrapolación de la realidad.

$\mathrm{Al}$ revés que la sátira social, el fondo irreal existe por si mismo, no para aplicaciones morales. La ciencia ficción puede definirse como la rama de la literatura que trata de las respuestas de los seres humanos a los progresos de la ciencia y de la tecnología (ASIMOV, 1982, p. 17).

Es posible confundir sátira social con ciencia ficción porque sus autores emplean los avances científicos como elementos de crítica ("Un mundo Feliz" de A. Huxley y "1984" de G. Orwell). La fantasía también recurre a la ciencia y lamentablemente ha provocado una subestimación del género. En su inmensa mayoría ni los dibujos animados, ni las aventuras de historietas, ni las películas de Hollywood representan auténtica ciencia ficción. Aunque la literatura fantástica necesita de lo nuevo, la etiqueta no puede aplicarse a cualquier tipo de mercadería.

Hubieron precursores y fundadores, en el caso de los primeros no había conciencia de estar escribiendo dentro de un género, en los segundos, se va precisando esa conciencia ya que cuentan con una prensa periódica de difusión masiva. Las obras precursoras de la ciencia ficción, todas anteriores al siglo XIX, tienen que ver con mentes especulativas y están muy relacionadas con la sátira social. Aunque debemos considerar a los relatos que recién desde el siglo XVII incorporan datos científicos, ya que a veces se suelen incluir todos los antecedentes utópicos y mitológicos de la humanidad. De modo que podemos partir desde Kepler y su famoso "Somnium" (1634), y otros viajes a la Luna como el de Cyrano de Bergerac. Ya en el siglo XVIII, Jonathan Swift y Voltaire reflejan a la perfección el espíritu del iluminismo mezclando las especulaciones filosóficas con el lenguaje científico de la época.

En el siglo XIX los adelantos de las técnicas gráficas y la educación obligatoria, sobre todo en EEUU, Inglaterra y Francia, crearon un enorme mercado lector principalmente de periódicos. La difusión masiva de libros y periódicos fue el marco para los fundadores de la ciencia ficción. Estos fueron J. Verne, H. G. Wells y J. Rosny Ainé, sus narraciones se basaron en la ciencia conocida y estuvieron influenciadas por el espíritu positivista de su tiempo. Presentaban diferencias y matices que caracterizaron a estilos del género y que persisten hasta el día de hoy. Verne pretendía aplicar los conocimientos de forma estricta, tal como actualmente 
lo hace la ciencia ficción "hard", incluyendo intenciones didácticas. Wells produjo una renovación de la narración fantástica explicada con lo filosófico pero, a decir de Verne, "inventando" ciencia. Rosny Ainé incluyó en sus relatos la variante espiritualista y religiosa.

En el siglo XX emergieron revistas especializadas y fue Hugo Gernsback, editor en 1926 de la revista "Amazing Stories", quien acuñó el término "ciencia ficción". A partir de allí se atrajeron a escritores con fuertes calificaciones científicas y técnicas, aunque muchos de ellos fueran criticados por sus pobres habilidades literarias.

Buena Ciencia Ficción (Hard): La ciencia ficción no es ficción acerca de la ciencia, trata acerca de la gente, beneficiada o afligida por el impacto causado por los cambios científicos y tecnológicos. Pero coexisten diferentes perspectivas de concebir el género, desde quienes conceden mayor peso a lo fantástico, tratando a la ciencia de modo disparatado, hasta aquellos que analizan la evolución de las estructuras sociales siendo rigurosos con los conceptos científicos. Esta última modalidad ha sido llamada "hard" y será la "buena" ciencia ficción, adecuada para nuestros fines didácticos.

Para delimitar la "buena" ciencia ficción, debemos distinguirla de los demás géneros de la literatura fantástica por el tipo especial de plausibilidad que introduce, la que está directamente relacionada con los elementos científicos sólidos que emplea el autor. Por otra parte debe conservarse la "garantía científica" sin que esta domine a la auténtica historia de ficción. Un análisis mas profundo realiza Umberto Eco (1988) al proponer que el género establece una estructura conjetural del discurso, ya que todo juego de ciencia ficción representa una forma aventurada de conjetura científica: "Insisto sobre la ciencia ficción como narrativa de conjetura por un motivo bastante sencillo: la ciencia ficción buena es científicamente interesante no porque hable de prodigios tecnológicos, y podría incluso no hablar de ellos, sino porque se propone como juego narrativo sobre la propia esencia de toda ciencia, es decir, su conjeturabilidad. En otros términos, la ciencia ficción es una narrativa de la hipótesis, de la conjetura o de la abducción y en ese sentido es juego científico por excelencia, dado que toda ciencia funciona mediante conjeturas, esto es, abducciones."

Sabemos que los alumnos prestan mayor atención cuando el tema a estudiar se presenta de manera que para ellos sea de interés y relevancia. La ciencia ficción provoca una sensación de asombro y de maravilla e introduce la indagación de temas sociales y filosóficos ampliando la concepción de nuestro universo. En numerosos trabajos se ha señalado lo beneficioso que resulta en el aula la utilización de recursos didácticos motivadores como las artes plásticas, el cine y la literatura (MARTÍN-DÍAZ et al. 1992; GARCÍA-BORRÁS, 2006; CACHAPUZ, 2007; PALACIOS, 2007; SIERRA CUARTAS, 2007). Desde nuestro punto de vista, las narraciones de "buena" ciencia ficción pueden ser utilizadas por los docentes como estrategia para aumentar el interés de los estudiantes por los temas científicos además provocan en ellos procesos de reflexión y conceptualización.

Existen autores de todo tipo, los que simplemente crean situaciones de fantasías, plagadas de errores y dislates en cuestiones científicas, hasta los que producen "buena" ciencia ficción. Los aspectos negativos de los primeros muchas veces pueden ser revertidos en positivos si, con intención didáctica, realizamos en el aula una crítica a los conceptos erróneos. Pero son los segundos, los que desde el rigor científico imaginan posibles desarrollos y sus repercusiones sociales, quienes nos resultaran más útiles en nuestras propuestas docentes. Esta litera- 
Aproximación didáctica a la termodinámica ...

tura existe, podemos obtenerla y aprovecharla, aunque no sea tarea sencilla realizar una selección apropiada.

\section{Diseño metodológico de la investigación}

\section{Metodología didáctica}

Nuestra hipótesis de trabajo es que los estudiantes verán facilitada la comprensión de los conceptos de termodinámica si complementamos la instrucción con las figuras del lenguaje de la literatura de ficción, que son básicamente analógicas.

Participantes: un grupo de estudio constituido por los alumnos de un curso de último año de la escuela de nivel medio, $3^{\circ}$ año de Polimodal, con Orientación en Ciencias Naturales, 25 alumnos de 17 años de edad de la ciudad de Mar del Plata. El curso se desarrolló durante el segundo cuatrimestre del año 2006.

Diseño y Procedimiento: El diseño de esta investigación, cuyo objetivo fue tratar de identificar los logros conceptuales y las dificultades de los estudiantes para interpretar la naturaleza de la energía, sus transformaciones y su degradación, corresponde al de un estudio exploratorio a través del análisis de las respuestas de los alumnos a todas las actividades planteadas. Dichas actividades se realizaron en base a la lectura de dos cuentos de ciencia ficción y fueron de tipo abierto con énfasis en lo explicativo y cualitativo.

En el nivel medio de enseñanza, las concepciones de los estudiantes sobre conservación-degradación de la energía han sido escasamente investigadas. Esta situación se debe, por lo menos en nuestro ámbito, a que estos conceptos no llegan a dictarse a pesar de estar incluidos en los programas curriculares de ciencias naturales.

Un concepto con cierto grado de abstracción como el de entropía proviene sólo de la instrucción, por lo que no cabe realizar un estudio sobre concepciones alternativas o previas de los estudiantes. Si bien existen en ellos provenientes de años anteriores algunas ideas erróneas sobre calor y temperatura, dirigimos nuestro estudio hacia la indagación de cómo evolucionan los conceptos, estructurados en modelos explicativos, durante todo el período de desarrollo del tema.

La instrucción tuvo una duración de 20 horas de clase con el dictado del temario previsto para el estudio de la termodinámica (temperatura, energía interna, calor, primera y segunda ley, aspectos microscópicos y estadísticos), conjuntamente con la realización de guías de trabajos prácticos y sus evaluaciones.

$\mathrm{Al}$ promediar el curso contamos con la colaboración del profesor de literatura, con quien los alumnos leyeron los cuentos, hicieron un análisis literario sobre el tipo de relato así como ejercicios de comprensión de lectura. Finalmente respondieron el cuestionario de literatura (ver Anexo) en el horario de clase.

Al finalizar el curso los alumnos recibieron el planteo de un conjunto de actividades sobre los cuentos, cuyos resultados se utilizaron como evaluación del curso. De modo que leyeron nuevamente los textos y respondieron a cuestiones sobre termodinámica. Parte de las 
actividades las realizaron en el aula y parte en el hogar, con la facilidad de buscar información complementaria sobre cosmología y cristales en libros o en Internet.

\section{Metodología de evaluación}

Materiales y validación: La termodinámica se formula en dos niveles explicativos.

Para que esta situación no confunda a los estudiantes tiene que existir una correlación entre ambas representaciones, y en nuestra propuesta se abarcan ambos niveles descriptivos. Encontramos en los cuentos de "buena" ciencia ficción La última pregunta de Isaac Asimov (1992) y Los cristales de Ítalo Calvino (1985) la posibilidad de abordar el estudio de la termodinámica fenomenológica y los aspectos microscópicos y estadísticos de la materia.

Los instrumentos de evaluación (ver Anexo 1) se elaboraron en base a los textos de los cuentos seleccionados y consisten en actividades y preguntas abiertas. Como una validación parcial de la consistencia de los instrumentos, los contenidos y objetivos de las cuestiones han sido evaluados por profesores universitarios de física y por docentes investigadores en educación, quienes acordaron sobre el enfoque teórico. Se trabajó previamente con cuatro alumnos para comprobar la factibilidad de la propuesta así como la concordancia entre la comprensión de los enunciados y nuestras intenciones al formular las preguntas.

Recolección y organización de datos: Las explicaciones de los estudiantes, surgidas de las distintas actividades, las evaluamos según criterios fijados previamente. Las tareas de estudio literario, y los ítems 1 y 2 de cada uno de los cuentos se analizaron cualitativamente. El ítem 3 tuvo además una observación cuantitativa: las respuestas a las preguntas fueron agrupadas según dos esquemas principales, macroscópico y microscópico en donde se las seleccionaron dividiéndolas en seis renglones temáticos para abreviar esta representación, buscando las ideas principales de cada respuesta, Los datos se volcaron en una matriz.

\section{Análisis de los resultados}

Comentaremos sobre las concepciones de los estudiantes después de la instrucción a través de las respuestas a las cuestiones que figuran en el Anexo. A continuación se transcribe una selección de las respuestas.

\section{Actividades literarias}

Se puso énfasis tanto en las características del género como en el tema y el tipo de relato, favoreciendo las actividades interdisciplinarias e integradoras. Además se tuvieron en cuenta los problemas sociales que surgen del uso de la tecnología.

\section{Respuestas de los estudiantes, algunos ejemplos}

1) En el cuento "La última pregunta" los posibles avances de la ciencia que figuran son:

La máquina que se autocorrige y responde todas las preguntas. 
Aproximación didáctica a la termodinámica ...

La creación de una estación capaz de captar energía interestelar.

La conexión de la mente de las personas entre síy con las máquinas. Además conectadas a una máquina central que había ido evolucionando con el paso del tiempo.

2) Puede haber un mensaje sobre la deshumanización, en la que las mentes de las personas se fusionarán con las máquinas.

3) En el cuento "Los cristales" se entiende por desorden al estado en que se encuentran los átomos de sustancias no cristalinas. Parecido al mundo en que vivimos (es un orden aparente). El verdadero orden sería el mundo de cristal (la estructura de los cristales es ordenada, compleja, perfecta).

4) Porque presenta posibilidades cientificas dentro de un mundo ficticio (ocupar otras galaxias, interconexión de las mentes).

5) "Cuando bajamos de la nave todo estaba en silencio", esos seres extraños y pegajosos ya se habian marchado. Mientras recordaba esa gran batalla que habia ocurrido sólo 3 días antes, preparaba mi ultra-arma XT15 para volver a tierra saturniana y terminar con todo. La batalla final por Saturno se acercaba y las presiones eran demasiadas. Nuestra nave tocó la roca árida y en unos segundos bombas, flechas y distintas armas nos atacaban provenientes de las montañas. El Sol ardía y nos encontrábamos solos...

\section{Cuento A. Ítem 1:}

\section{Proceso espontáneo - Irreversibilidad}

"Los dos sabemos que la entropía no puede revertirse. No puedes volver a convertir el bumo y las cenizas en un árbol"

"Todo comenzó con la explosión cósmica original, fuera lo que fuese, y todo terminará cuando las estrellas se extingan".

\section{Degradación de la energía - Aumento de la entropía}

"Por mejor que se la administre, la energía gastada desaparece y no puede ser repuesta. La entropía aumenta cotidianamente".

"Pero en un trillón de años estaremos a oscuras. La entropia tiene que incrementarse al máximo".

\section{Cuento B. Ítem 1:}

\section{Orden y desorden}

"La sustancia de las cosas cambiaban en torno a nosotros de un minuto a otro, o sea que los átomos pasaban de un estado de desorden a otro de desorden y después a otro: es decir, que en la práctica todo seguía siempre igual. El único cambio verdadero habría sido el disponerse de los átomos en un orden cualquiera".

"...una regularidad en el sistema, o una compenetración de sistemas diversos pero sin embargo mensurables aunque incongruentes, de modo de hacer ensamblar en cada granulosidad del desorden la faceta de un orden que en seguida se desmesura...".

"...felicidad viendo como toda la sustancia que componía el mundo encontraba su forma definitiva y sólida, y un temor todavía indeterminado de que este triunfo del orden en formas tan variadas pudiera reproducir en otra escala el desorden que acabábamos apenas de dejar a nuestras espaldas". 


\section{Formación de cristales - Visión microscópica}

"Si las sustancias que constituían el globo terrestre en estado incandescente hubieran dispuesto de un tiempo suficientemente largo para enfriarse y de suficiente libertad de movimiento, cada una de ellas se habría separado de las otras en un único, enorme cristal".

"Señalaba, en medio de una cordura de lava, algo que estaba tomando forma. Era un sólido de fases regulares y lisas y ángulos cortantes, y esas fases y ángulos lentamente se iban agrandando como a expensas de la materia en torno, e incluso la forma del sólido combinaba, pero manteniendo siempre proporciones simétricas... Y no solo la forma era la que se distinguía de todo el resto; era también el modo en que la luz penetraba, atravesándola y retractándose".

"... ahora subian a la superficie cubos, octaedros, prismas, figuras diáfanas que parecian casi aéreas, vacias por dentro, y que en cambio, como se vio enseguida, concentraban en si mismas una increíble compacidad y dureza".

"... prismas con cúspides agudas con ejes horizontales y verticales que atraviesan el sólido compacto. Poseen lados y aristas, lisas paredes transparentes y ángulos simétricos. Poseen una forma regular, un eje de rotación y una constancia en los diedros...".

\section{Cuento A. Ítem 2:}

"Casi todas las estrellas eran enanas blancas en disolución"

"Para mi esta frase del cuento hace referencia a la extinción de las estrellas enanas de las cuales se utilizaba la luzy se la transformaba en energía útil de algún tipo. Una vez extintas, quedan solo las estrellas que no tienen muchos años de utilidad y que no tienen demasiada importancia. Físicamente bablando podemos decir que la frase busca dar a conocer la situación de la entropía del sistema. Mencionando que eran enanas blancas, está diciendo que esas estrellas no son de gran utilidad por tener un bajo contenido energético.

"Una enana blanca es un remanente estelar que resulta del agotamiento del combustible nuclear de una estrella de masa no mayor a unas 10 masas solares. A partir de la disolución de estas, se crean nuevas estrellas con el polvo que habia entre ellas. Se construye una sola estrella por cada mil estrellas enanas blancas destruidas".

"La extinción de una gran cantidad de enanas blancas, de baja energía, generará otra estrella de la que también podrá extraerse energía. Pero las estrellas generadas serían cada vez. más débiles y menos energéticas conduciendo necesariamente asi a la muerte del universo."

"La última estrella oscura rodeada de materia increíblemente fina que descendía asintóticamente hacia el cero absoluto"

"Esta frase hace referencia a la muerte térmica del Universo, cuando ya todas las estrellas existentes se habrán extinguido y la energía cósmica se reduce simplemente a la de una sola estrella. Esta sería de poca calidad energética y, a su vez, estaría perdiéndola constantemente haciendo aumentar la entropia al máximo. Una vez que la energía es distribuida por completo, la calidad energética del sistema y la temperatura tienden a cero hasta que en un momento vale cero".

"La última estrella oscura, sólo poseía restos de un calor que se gastaba hasta llegar a la temperatura más baja posible, el cero absoluto, y con esto la muerte térmica del Universo". 
Aproximación didáctica a la termodinámica ...

\section{Cuento B. Ítem 2:}

"Dime si sin la intrusión de átomos extraños habría rubies"

"Esta frase hace referencia a la formación de los rubies. Para que una gema natural como el rubi pueda formarse es necesaria la interacción no de uno o dos, sino varios elementos constituidos de diferentes grupos de átomos.

"Para formar cristales artificialmente, es necesario que intervengan otras sustancias, otros átomos extraños como por ejemplo alúmina o criolita. De este modo los rubies no existirían sin la incorporación de átomos extraños".

"Las sustancias absorben calor y a grandes temperaturas se funden permitiendo que las moléculas se separen y los átomos queden sueltos. Los átomos se reubican de tal manera que al enfriarse conforman una masa y una estructura de composición y "color del rubi". Los átomos extraños son aquellos que componen las sustancias que se desintegran por la temperatura contenida y suministrarán el color del rubi."

\section{Cuento A. Ítem 3:}

(Aa y Ab) - Conservación de la energía - Los estudiantes exponen de forma declarativa, a través de ejemplos y en el contexto sugerido por el cuento, sus conceptos de conservación y transferencia de la energía. El número de respuestas correctas confirma que la mayoría de los estudiantes ya han asimilado el principio de conservación.

"Las actuales fuentes de energía son la atómica, cinética, eólica, geotérmica, bidráulica, nuclear, solar, termonuclear. Un sistema abierto intercambia energía con el ambiente de forma dual".

"La energía solar es la energía radiante producida en el Sol como resultado de reacciones nucleares de fusión. Llega a la Tierra a través del espacio, transformada en cuantos de energía llamados fotones que interactúan con la atmósfera y la superficie terrestre, en parte como energía calórica".

(Ac y Ad) - Degradación de la energía - En estas preguntas se trata de indagar sobre el hecho de que sabiéndose sobre la evolución de las estrellas se plantea que la cantidad de energía disponible disminuye constantemente, porque se transfiere de los cuerpos calientes a los fríos. En algunos estudiantes la explicación de estos fenómenos no tiene en cuenta el intercambio de calor entre el sistema (la estrella) y el resto del Universo.

"Hasta el día de hoy, el Sol ha consumido aproximadamente la mitad del hidrógeno útil, y brillará como lo conocemos otros cinco mil millones de años, esto sucederá cuando su energía interna se agote. El final de la vida estable del Sol llegará cuando su núcleo no contenga bidrógeno. En ese momento, al dejarse de producir energía, el núcleo empezará a contraerse otra vez, como lo hizo la nube original diez. mil millones de años antes".

"El Sol es una estrella, por lo tanto las estrellas se agotarán al igual que el Sol teniendo en cuenta que tienen las mismas características. El tiempo de vida de cada estrella depende, entre otras cosas, de cuanto bidrógeno disponga". 
(Ae, Af y Ai) - Irreversibilidad - Aumento de la entropía - Las explicaciones ya denotan una correlación entre los dominios de la fenomenología y del modelo microscópico. Partiendo desde la concepción de un sistema aislado, que no puede mantenerse en movimiento perpetuo, hasta la de su evolución hacia una configuración en la que cada parte del sistema tendrá la misma cantidad de energía. Así, si dos sistemas intercambian energía en forma de calor, evolucionan hacia la misma temperatura.

"La entropía es la evolución irreversible de los sistemas hacia los estados más probables. Es la medida de la calidad energética. La entropía puede calcularse para un sistema aislado, éste siempre evoluciona hacia las configuraciones que tienen más estados. Según el texto del cuento la energía se va gastando y la entropía aumenta continuamente, incrementándose al máximo".

"Un proceso espontáneo es aquel que tiene una tendencia natural a ocurrir por su propia disposición. Todo lo que es espontáneo es lo posible, algo no espontáneo sería que de repente unos pedazos de vidrio roto se unieran y formaran un vaso. En el cuento el proceso espontáneo es la utilización de la energía solar y su agotamiento".

\section{Cuento B. Ítem 3:}

(Ba, Bb y Bc) - Orden y desorden - En el nivel microscópico, en general los estudiantes no superponen los referentes empíricos con las interpretaciones basadas en la estructura de la materia. El incremento de entropía se asocia con un incremento del desorden del sistema aislado, que evoluciona de forma natural hacia las configuraciones más probables.

"El incremento de la entropia tiene que ver con una disposición que aumenta su desorden. En los cristales el orden es grande y la entropía es baja. Claro está que en el cuento se alude al orden de los cristales contrapuesto al desorden del mundo que vivimos".

"De forma espontánea es casi nula la probabilidad de que un proceso vaya del desorden al orden. Lo contrario puede ocurrir si el sistema no está aislado, con un gasto de energía de otro sistema, que aumentará su desorden".

(Bf y Bh) - Visión microscópica - Cero absoluto - Se comprueba que las respuestas de los estudiantes en este caso pueden utilizar más de una categoría explicativa. Aquí, la mayoría entiende la dependencia de la entropía con el número de posibilidades de organización de los átomos.

"En una estructura cristalina, la entropía toma un valor muy pequeño. Esta tiende a cero si la temperatura llegara al cero absoluto".

"Es un reticulado de átomos que se repite de continuo, periódico. El personaje del cuento dice que es regular, simétrico, una constancia en los diedros".

(Bj y Bk) - Cristales - Imperfecciones - En este caso, las respuestas de los estudiantes, descriptivas y obtenidas desde referencias bibliográficas, están encuadradas en un nivel de interpretación caracterizado por explicaciones de "funcionamiento microscópico". 
Aproximación didáctica a la termodinámica ...

"Las imperfecciones de un cristal pueden ser modificaciones de la estructura cristalina que altera su periodicidad. O también relacionadas con su composición quimica, por tener dentro de su estructura átomos pertenecientes a otras sustancias que modifican sus caracteristicas".

"Los cristales semiconductores no presentan propiedades prácticas. Pero si se los "contamina" con elementos pentavalentes como el As o Sb se crean modificaciones en la distribución de cargas eléctricas, centros de recombinación, que les dan propiedades necesarias para fabricar transistores o diodos utilizados en los dispositivos electrónicos".

\section{Resultados}

Las cuestiones propuestas se refieren a fenómenos termodinámicos relacionados con conceptos que clasificamos en dos niveles representacionales, los que se estructuran como categorías explicativas. Estas dos categorías, macroscópica y microscópica, están relacionadas directamente con las dos perspectivas científicas de la termodinámica. La interpretación a través de ambos modelos nos brinda una idea del aprendizaje conceptual principalmente cuando notamos una correlación del mismo concepto entre niveles. En la Tabla 1 nos abocamos en distinguir entre respuestas correctas e incorrectas con el fin de estudiar la progresión de la conceptualización.

Tabla 1. Progresión de la conceptualización.

\begin{tabular}{lllccc}
\hline & \multicolumn{1}{c}{ Tema conceptual } & Preguntas & Correcto & Confuso & Incorrecto \\
\hline \multirow{3}{*}{ Macroscópico } & Conservación de la energía & $\mathrm{Aa}, \mathrm{Ab}$ & 19 & 6 & - \\
& Degradación de la energía & $\mathrm{Ac}, \mathrm{Ad}$ & 17 & 6 & 2 \\
& Irreversibilidad - Aumento de la entropía & $\mathrm{Ae}, \mathrm{Af}, \mathrm{Ai}$ & 18 & 4 & 3 \\
\multirow{3}{*}{ Microscópico } & $\mathrm{Ba}, \mathrm{Bb}, \mathrm{Bc}$ & 17 & 5 & 2 \\
& Orden y desorden & $\mathrm{Bf}, \mathrm{Bh}$ & 19 & 4 & 2 \\
& Visión microscópica - Cero absoluto & $\mathrm{Bj}, \mathrm{Bk}$ & 20 & 5 & - \\
\hline
\end{tabular}

Finalmente, para evaluar las relaciones de vínculo entre los conceptos involucrados en ambos modelos y en ambos cuentos, comparamos las respuestas Ae-Af-Ai con las respuestas $\mathrm{Ba}-\mathrm{Bb}-\mathrm{Bc}$. Observamos un alto grado de coherencia conceptual (75\%), y una correlación entre la interpretación energética y probabilística de la entropía.

Respecto de las ideas confusas e incorrectas se deben destacar la persistencia en varios alumnos de las concepciones espontáneas ya detectadas durante el curso. Como ha señalado Bachelard (1993) existe un perfil epistemológico de los diversos conceptos, de modo que las ideas confusas se refieren a una mezcla de epistemología espontánea de los hechos cotidianos con criterios científicos obtenidos durante la instrucción.

Estas concepciones espontáneas tienen varias facetas. La comparación con las acciones humanas como intención, esfuerzo y "razón suficiente", serían una condición intuitiva para comprender los fenómenos a través de relaciones causales. Otra explicación espontánea 
de índole general es la teleología. Por otra parte la estructura de la materia es interpretada de forma intuitiva a través de un conjunto de suposiciones básicas sobre las propiedades de las sustancias y sus transformaciones, como el esencialismo, el sustancialismo y la continuidad. Analizaremos dos respuestas:

- 3er respuesta del Ítem 2- Cuento A ("La extinción de una gran cantidad .....)

Aquí el razonamiento del alumno implica que el sistema de estrellas evoluciona en una dirección determinada a través de un intermediario, la energía. Si bien coincide con la segunda ley de la termodinámica, sus palabras sugieren que al estudiante le resulta difícil concebir que hay procesos dinámicos sin agentes "activos" o "pasivos", y sin direccionalidad. Su sentido común está basado en procesos heurísticos que lo guían en la versión más elemental de la causalidad, sólo vinculada con los aspectos temporales. Y este mismo razonamiento lo lleva a la teleología, que presupone que esos cambios ocurren para satisfacer algún fin o necesidad determinada o algún principio más fundamental, como la muerte del universo.

- 3er respuesta del Ítem 2- Cuento B ("Las sustancias absorben calor y .....)

El estudiante utiliza el "esencialismo" es decir que aplica el proceso de aditividad para explicar el color del cristal, así como otras propiedades "emergentes". Pero tales propiedades de los componentes individuales desaparecerán cuando se descompone el sistema. Estos atajos en el razonamiento tienden a generar respuestas intuitivas con poco esfuerzo. Como ocurre también con la "continuidad" de las propiedades de la materia, ya que supone que las sustancias pueden ser divididas continuamente en piezas más pequeñas cualitativamente iguales a la totalidad. También se nota el "sustancialismo", al concebir como sustancias a entidades abstractas y procesos de transferencia como el calor, la "temperatura contenida" o el color adquirido por el rubí.

\section{Consideraciones finales}

Los resultados obtenidos nos muestran que se produjo una actitud favorable y receptiva de los estudiantes al enfrentarse con las actividades programadas. Este desafío les resultó motivador y entretenido pudiendo confirmarse que el uso de la narrativa en el aula, a través de las metáforas conceptuales que genera, produce efectos significativos en la comprensión de los alumnos. Las metáforas conceptuales son constructos provisorios, son estados generativos, ya sean declarativos o procedimentales, que deben ser procesados a través de la instrucción sin disminuir las características conceptuales del modelo teórico.

Sabemos que el modo de elaboración del conocimiento científico no es espontáneo, de modo que la apropiación de los conceptos depende del cuadro epistémico que guía las actividades cognitivas de los estudiantes (HEWSON, 1985; HAMMER, 1994). Así, constatamos que la intervención didáctica del profesor y las estrategias empleadas influyeron en el aprendizaje de los estudiantes.

Comprobamos que, aunque a muchos les sorprenda, no se debe atribuir un nivel absoluto de dificultad a un tema o concepto en particular y la contribución y estrategia de un buen profesor será hallar las preguntas apropiadas o hacer que el alumno las plantee. Estas 
Aproximación didáctica a la termodinámica ...

preguntas deberán ser intermedias es decir que puedan responderse y llevar a otras preguntas. Además, el hecho de que las cuestiones propuestas fueran de enunciados abiertos les permitió abordarlos con una metodología de tipo investigativo, familiarizándolos con algunas facetas del trabajo científico y desarrollando procesos metacognitivos. Comprobamos que el motivo de utilizar la narrativa de ficción no es solamente para disparar el interés de los estudiantes por el tema tratado sino que representa una ayuda para aproximarlos a los modelos de la ciencia y también para favorecer la adquisición de conocimientos generales, como en este caso, sobre cosmología y la estructura cristalina de a materia.

Tal vez el mayor logro haya sido que los alumnos entendieran la correlación entre ambos modelos teoréticos, el microscópico (ligado a conceptos estadísticos) y el macroscópico (fenomenológico), y cómo éstos guardan entre sí una correspondencia entre sus descripciones. Propiciamos la utilización de la "buena" ciencia ficción como recurso educativo ya que si bien su búsqueda imaginativa encuentra un aliento metafísico, no da golpes bajos, no se aprovecha de las ansias de la gente de encontrar dimensiones misteriosas o deidades cósmicas. Por esas características, además de animar los procesos cognitivos de los alumnos, la ciencia ficción puede ser utilizada en otros aspectos relacionados con la valoración del pensamiento científico. Por una parte para desmitificar a la ciencia dentro del contexto social, y por otra, para diferenciarla de la pseudociencia. Asimismo, la sociedad no aprecia a la ciencia como una actividad cultural, y en ese sentido es considerada inferior al arte. Si la ciencia quiere ser admitida en un lugar concreto de nuestra sociedad la ciencia ficción, a través de sus cualidades comunicativas, puede representar en el aula un nexo significativo para la integración de las "dos culturas".

\section{Referências}

ALONSO, M.; FINN, E. An integrated approach to thermodynamics in the introductory physics course. Physics Teacher, Boone, NC, v. 33, n. 5, p. 296-310, 1995.

ASIMOV, I. Cuentos completos. Barcelona: Bruguera, 1992. v. 1. p. 333-344.

ASIMOV, I. ¿Hay alguien allí? Barcelona: Bruguera, 1982.

BACHELARD, G. E1 aire y los sueños. México: Fondo de Cultura Económica, 1958.

BACHELARD, G. La poética de la ensoñación. México: Fondo de Cultura Económica 1982.

CACHAPUZ, A. F. Arte y ciencia: ¿qué papel juegan en la educación en ciencias? Revista

Eureka sobre Enseñanza y Divulgación de las Ciencias, Puerto Real, Cádiz, v. 4, n. 2, p. 287-294, 2007.

CALVINO, I. Tiempo cero. Barcelona: Minotauro, 1985.

DE JONG, G. An introduction to explanation-based learning. In: SHROBE, H. E. (Ed.). Exploring artificial intelligence. San Mateo: Morgan Kauffman, 1988. p. 36-54. 
Zamorano, R. O.; Moro, L. E.; Gibbs, H. M.

ECO, U. De los espejos y otros ensayos. Barcelona: Lumen, 1988.

EGAN, K. La imaginación en la enseñanza y el aprendizaje: para los años intermedios de la Escuela. Buenos Aires: Amorrortu, 1999.

EYLON, B.; LINN, M. C. Learning and instruction: an examination of four research perspectives in science education. Review of Educational Research, Washington, v. 58, n. 3, p. 251-301, 1988.

ERICKSON, G. L. Children's conceptions of heat and temperature. Science Education, Filadelfia, PA, v. 63, n. 2, p. 221-230, 1979.

GALAGOVSKY, L.; ADÚRIZ-BRAVO, A. Modelos y analogías en la enseñanza de las ciencias naturales. El concepto de modelo didáctico analógico. Enseñanza de las Ciencias, Barcelona, v. 19, n. 2, p. 231-242, 2001.

GARCÍA-BORRÁS, F. J. Cuando los mundos chocan. Revista Eureka sobre Enseñanza y Divulgacion de las Ciencias, Puerto Real, Cádiz, v. 3, n. 2, p. 268-286, 2006.

GARNHAM, A.; OAKHILL, J. Thinking and reasoning. Oxford: Blackwell, 1994.

GOSWAMI, U.; BROWN, A. L. Melting chocolate and melting snowmen: analogical reasoning and causal relations. Cognition, York, v. 35, n. 1, p. 69-95. 1990.

HALFORD, G. S. Children's understanding: the development of mental models. Hillsdale: Lawrence Erlbaum, 1993.

HAMMER, D. Epistemological belief in introductory physics. Cognition Instruction, Reading, v. 12, n. 2, p. 151-183, 1994.

HEWSON, P. W. Epistemological commitments in the learning of science: examples from dynamics. International Journal of Science Education, Reading, v. 7, n. 2, p. 163-172, 1985.

LAKOFF, G.; JOHNSON, M. Metáforas de la vida cotidiana. Madrid: Cátedra, 1991.

MARTÍN-DÍAZ, M. J. et al. Science fiction comes into the classroom: Maelstrom II.

Physics Education, Bristol, v. 27, n. 1, p. 18-23, 1992.

MARTÍNEZ, J. M; PÉREZ, B. A. Estudio de propuestas alternativas en la enseñanza de la termodinámica básica. Enseñanza de las Ciencias, Barcelona, v. 15, n. 3, p. 287-300, 1997.

MICHINEL J. L; D’ALESSANDRO, M. A. El concepto de energía en los libros de texto: de las concepciones previas a la propuesta de un nuevo lenguaje. Enseñanza de las Ciencias, Barcelona, v. 12, n. 3, p. 369-379, 1994.

OLIVA, J. M. et al. Una propuesta didáctica basada en la investigación para el uso de analogías en la enseñanza de las ciencias. Enseñanza de las Ciencias, Barcelona, v. 19, n. 3, p. 453-470, 2001.

PALACIOS, S. L. El cine y la literatura de ciencia ficción como herramientas didácticas en la enseñanza de la física: una experiencia en el aula. Revista Eureka, Puerto Real, Cádiz, v. 4, n. 1, p. 106-122, 2007. 
Aproximación didáctica a la termodinámica ...

SIERRA CUARTAS, C. E. Fortalezas epistemológicas y axiológicas de la ciencia ficción: un Potosí pedagógico mal aprovechado en la enseñanza y la divulgación de las ciencias.

Revista Eureka, Puerto Real, Cádiz, v. 4, n. 1, p. 87-105, 2007.

SOLBES, J.; TARÍN, F. Algunas dificultades en torno a la conservación de la energía.

Enseñanza de las Ciencias, Barcelona, v. 16, n. 3, p. 387-397, 1998.

ZAMORANO, R. O. et al. Evaluación de un modelo didáctico analógico para el aprendizaje de energía interna y temperatura. Revista Eureka, Puerto Real, Cádiz, v. 3, n. 3, p. 392-408, 2006. 
Zamorano, R. O.; Moro, L. E.; Gibbs, H. M.

\section{Anexo 1}

\section{ACTIVIDADES LITERARIAS}

1) Elige uno de los cuentos y menciona elementos del texto relacionados con posibles avances de la ciencia.

2) A través de la ficción de la historia ¿cuál puede ser el mensaje del texto?

3) En el cuento de los cristales ¿qué entienden por orden y desorden?

4) ¿Por qué ese cuento puede leerse como ciencia ficción?

5) Elegir una de estas alternativas para una narración de ciencia ficción

- Cuando bajamos de la nave, todo estaba en silencio...

- De pronto un extraño se aproximó a nuestro refugio...

- Habían transcurrido desde entonces 1700 años...

\section{Cuento A: "La última pregunta" de Isaac Asimov}

Resumen del cuento

A través de una secuencia de siete relatos, que van desde un futuro próximo hasta la muerte térmica del Universo se discute sobre el crecimiento de la entropía. La humanidad se propaga por el espacio ocupando primero el sistema solar, luego nuestra galaxia y finalmente todo el cosmos. A medida que esto sucede, se agota el sol y van muriendo las estrellas. En cada época los personajes van analizando la energía disponible en el universo y su degradación. Preguntan a la correspondiente supercomputadora si el proceso de aumento de la entropía se podrá revertir. No se obtiene respuesta, hasta el final.

\section{A-1) Encuentre ejemplos mencionados en el cuento acerca de los siguientes conceptos físicos.}

Fuente de energía - Conservación de la energía

Degradación de la energía - Aumento de la entropía

Sistemas abiertos y cerrados

Procesos espontáneos - Irreversibilidad

Muerte térmica del Universo - Cero absoluto

Flecha del tiempo - Espacio y Tiempo

\section{A-2) Dar una explicación breve de las siguientes frases.}

Pag.342: "Casi todas las estrellas eran enanas blancas en disolución".

Pag.344: "La última estrella oscura rodeada de materia increíblemente fina que descendía asintóticamente hacia el cero absoluto."

\section{A-3) Responda las siguientes cuestiones.}

a) ¿Cuáles son las actuales fuentes de energía?

b) ¿Qué es la energía solar?

c) ¿El sol se agotará? ¿Cuándo?

d) ¿Las estrellas se agotarán? ¿Cuándo?

e) ¿Qué es la entropía y por qué crece?

f) ¿Qué es un proceso espontáneo?

g) ¿Qué es un sistema abierto? ¿Y uno cerrado?

h) ¿Cuántas estrellas hay en una galaxia? ¿Cuántas galaxias hay en el Universo?

i) ¿Qué significa revertir el caos para volver al cosmos?

j) Si no hay materia y energía, ¿existe el espacio y el tiempo? 


\section{Cuento B: "Los cristales" de Italo Calvino}

Resumen del cuento

El personaje del cuento, QFWFQ es un ser intemporal que ha sido testigo de la evolución del universo (y de la formación de la Tierra). Actualmente vive en New York. Evoca el crecimiento de los cristales, que desde un "desorden" inicial lleva a la "ordenada" disposición de los átomos. Sabe que los cristales tienen imperfecciones pero le gustaría una regularidad perfecta. Su mujer Vug, como su esposa actual u otra ocasional mujer, prefieren las irregularidades, las que por ejemplo, provocan hermosos efectos en las piedras preciosas. Ahora observa la arena, el granito, las falsas simetrías del vidrio, es decir, la victoria definitiva de Vug representada en cristales contaminados por impurezas, como en el caso del transistor.

\section{B-1) Encuentre ejemplos mencionados en el cuento acerca de los siguiente conceptos físicos.}

"Orden" y "desorden"

Procesos espontáneos - Irreversibilidad

Formación de cristales - Visión microscópica

Entropía de un cristal

Imperfecciones y contaminación de un cristal

B-2) Dar una explicación de la siguiente frase.

Pág.46: "Dime si sin la intrusión de átomos extraños habría rubíes".

\section{B-3) Responda las siguientes cuestiones.}

a) ¿Qué se entiende por "orden" y "desorden"?

b) ¿Cómo un líquido o un gas incandescente pueden convertirse en un cristal?

c) ¿Puede haber un proceso que vaya del "desorden" al "orden"?

d) ¿Qué es un proceso espontáneo?

e) ¿Qué es la entropía?

f) ¿Qué es la entropía de un cristal?

g) ¿Por qué dice el personaje que el vidrio es vil y que tiene simetrías falsas?

h) ¿Cómo es la conformación microscópica de un cristal?

i) ¿Qué ejemplos aparecen de piedras preciosas?

j) ¿Qué son las imperfecciones de un cristal?

k) ¿Qué son las contaminaciones de un cristal?

I) Dar ejemplos de cristales naturales y artificiales.

Artigo recebido em dezembro de 2009 e aceito em maio de 2010. 